Digital Press Social Sciences and Humanities

Organizational Change and The Human Resource Challenges in Facing Technology Development

Theda Renanita and Fathul Himam

Proceeding of The 10th International Conference of Indigenous and Cultural Psychology 2019

Kwartarini Wahyu Yuniarti, Donald H. Saklofske, Rosnah Ismail, Saadi Lahlou (eds) 


\title{
Organizational Change and The Human Resource Challenges in Facing Technology Development
}

\author{
Theda Renanita ${ }^{1, *} \&$ Fathul Himam ${ }^{2}$ \\ 1 Fakultas Psikologi Universitas Ciputra \\ 2 Fakultas Psikologi Universitas Gadjah Mada \\ *e-mail: trenanita@gmail.com
}

\begin{abstract}
Technology continues to advance. This development began during the hunting era, followed by the agricultural era, the industrial era, and the era of information technology. In Indonesia, most organizations are still adjusting to the process of adopting information technology in organizational activities. The purpose of this article is to discuss the situation that is being experienced by organizations in Indonesia, as well as the human resources management (HRM) strategies used in facing this technology change. The results of this study show that organizations in Indonesia are changing as a result of technology adoption. These changes include changes in how and where employees work, changes in management roles, changes in occupation as well as business changes. Changes in various areas can affect employee performance. That being said, in managing human resources, HRM plays an important role. In carrying out its role, HRM must be able to integrate technology into its activities such as in selection and recruitment, learning and development, performance management, organizational effectiveness, compensation and payroll systems as well as workforce planning strategies. This study provides insight into the changes being experienced by the organization and how the role of HRM changes in response to the use of technology in improving work performance.
\end{abstract}

\section{Keywords}

human resources management, organizational change, technology

\section{Introduction}

The society continues to experience rapid development. Three eras mark the development of society, that is the agricultural era, the industrial era, and the digital era (Cascio \& Montealegre, 2016). During the agricultural era, people survived by using natural forces such as the wind, water, land, livestock, and elements related to agriculture. At the time, economic power was held by farmers who had extensive and fertile agricultural land. In the industrial era, steam engines and fuels were core infrastructure of the industrial processes. Factories that produce mass products emerged in this era. This encouraged the beginning of relations between producers, distributors, and consumers. Following the industrial era is the invention of technology that drives the emergence of the digital era. Some of the most critical infrastructures of this era belong to the category of information and communication technology. Digital resources can be accessed, stored, and transferred and stored anytime and anywhere. The use of digital technology facilitates the mechanism of control, coordination, and collaboration between companies or divisions within an organization.

This article will focus on the development of digital technology. There were three stages of the development of information and communication technology. First, enterprise computing, which is the use of computers as a space to store and process information. At the beginning of its development, computers were expensive; hence the numbers of computers owned by organizations were limited. As a result, one computer is shared by many employees. Then came the second stage, which was the strategy of using computers in what is called end-user computing. Organizations began to facilitate employees with personal computers. Thus, it was expected that employee productivity would increase. The next stage is marked by the development of a global network that uses communication technology. This stage is called strategic computing. During this era, different computers can be connected (Hauben \& Hauben, 1995). This era also sees a combination of technology and trade. 
There are two types of technology: sustaining technology and disruptive technology (Christensen, 1997). Included within the sustaining technology category are technologies that are continually enhanced to improve existing technology, not to create new ones. For example, computers with Intel processors started from static RAM, microprocessors, Intel 1 to Intel 4, and Dual Core to i7 processors. Whereas disruptive technology interferes with the performance of the previous technologies, can only be accessed by limited circles, and does not yet have a proven practical application. Disruptive technology creates new markets or new values. Examples of disruptive technology are Gojek and Grab which disrupt the conventional transportation business.

This unavoidable advancement of technology certainly has an impact on human civilization, especially for organizations that involve human resources. In today's organizations, human resources play not only a supportive role but also a strategic role (Dubravska \& Solankova, 2015). Through their knowledge, skills, and abilities, human resources are essential contributors to improving organizational competitiveness and performance. Therefore, organizational quality depends on the quality of human resources. The use of technology in organizations intersects with the activities of the workforce. This article aimed to identify the effects of technological advances on organizations and the challenges faced by Human Resources Management in managing the workforce.

\section{Application of Technology in Organizations}

According to Heltzel (2018), there are various applications of technology in organizations, such as:

a) The use of video, video conferencing dan virtual reality in communicating within organizations. Through these facilities, employees within an organization can conduct face-to-face communication with other members of their team who may be far away. In the United States, several large corporations have used virtual reality technology, for instance, Boeing and Walmart (Morris, 2018).

b) Internet of things (IoT) that involves connectivity, which is essential in business management. IoT can be utilized in various ways, from gathering to the automation of equipment and infrastructure that supports work. The use of IoT is increasingly common relative to other types of technology. Several companies that use IoT are PINS Indonesia, eFishery, dan Singapore Power (Lago, 2018).

c) Voice control and virtual assistants that involve language processing and integration with clouds allow the increase of work productivity. Examples of virtual assistants are Google Assistant, Alexa, and Cortana (Pickard \& Whitehead, 2019).

d) Computer vision is used to monitor and record shopping behavior to the choice of payment methods. Examples of companies that use this technology are Amazon and Fed-Ex.

e) Artificial intelligence is a technology that can record and process information. AI can also provide recommendations. In hotel companies, AI can be used to send information to customers about the current weather or also recommend places to eat. This information can be directly received by people who are detected to be around the hotel.

f) Blockchain or ledger technology is often used in the financial sector. A ledger technology that uses blockchains improves the efficiency and traceability of transactions (Keidanren Policy \& Action, 2018).

\section{Implications of The Use of Modern Technology in Organizations}

The use of digital technology leads to the integration of human resources, people, and technology itself. As an implication, the integration of these three things lead to transformation in the following areas:

a) How and where to work

A new generation, generation $Y$, has now become part of organizations. Generation $\mathrm{Y}$ is considered as a generation that is familiar with technology and has high collaborative skills (Ferri-Reed, 2014). The stereotypes inherent to generation $Y$ are that they are bad and have a superior attitude.

On the other hand, old employees are dominated by generation $\mathrm{X}$ who have different characteristics to generation Y. Generation X employees must adapt to the use of technology. It seems that generational differences within organizations require organizations to use different strategies when approaching employees.

Each employee becomes an expert in their respective cubicles. On the other hand, organizations demand communication between teams. With technology, employees can interact with each other 
wherever and whenever. Employees can continue to work together remotely. Such conditions open opportunities for collaboration, which is an essential key in organizations (Robertson, 2000).

The use of artificial intelligence in regulating the workspace can create a humanistic workplace. Room temperature or lighting can also be automatically adjusted to the conditions of employees in the room. The use of AI in a room or workplace setting can help calibrate comfort in employees' workplace and manage the efficiency of a room (Efron, 2017).

b) Changes in work

According to Sohag (1992), technology changes the work patterns. It is said that human relations depend on how meaningful social relations are built within an organization. If the use of technology hinders the formation of groups people have chosen for themselves, inter-group cohesion will be disrupted. However, if technology enables employees to use their skill set, reduces supervision, and increases the autonomy of the working groups, then the organization will be efficient.

Moreover, the use of new technology has driven work change due to the demand of increasing intellectual skills and capacity. As a result, there is an increase in the demand for multi-professional workers who are educated and meet job requirements. With this, a shift in work culture from manual or clerical to intellectual work has occurred. Therefore, organizations must continue to provide opportunities for employees to be able to learn new skills.

c) Changes in business activities

The use of technology has also changed the activities of companies. According to Pagani \& Pardo (2017), there are three business activities: 1) an activity-links-centered type of digitalization. The main activity of this type of company is to coordinate company activities using existing technology, not to create new activities but to optimize existing activities. An example of this type of company is Biomérieux use of technology to facilitate B2B tracking. 2) A resource-ties-centered type of digitalization, where the use of technology creates new activities in the company. For example, the collaboration between IBM and Dassault Systems, where the two companies initially work in different lines of businesses but were able to collaborate to produce a digital diagnostic tool. 3) An actor-bondscentered type of digitalization, characterized by coordination between companies that produce transaction costs. Companies that are involved build connectivity and recombination. An example of this type of company is a marketplace (Pagani \& Pardo, 2017).

d) Organizational decision making

Decision making is based on knowledge. In organizations, knowledge is co-created by members of the organization, not only by managers but also by staff and stakeholders. The use of technologies such as AI can produce large volumes of data or what is called big data. Big data allow the opportunity for organizations to find hidden knowledge, generate new knowledge, and improve analytical skills (Vorley, 2017). Big data enables knowledge sharing between and within everyone in organizations. This knowledge comes from empirical data retrieved from the field (Acharya \& Singh, 2018).

e) Selection and recruitment processes

Selection and recruitment processes require time and money. However, using artificial intelligence, selection, and recruitment processes can be easier. The process of everything between screening profiles of employee candidates to conducting interviews can be carried out by robots. The company can then retrieve the selection data from the AI robot and use it as a consideration for recruiting new employees who fit the company profile.

\section{Challenges that Emerge for Human Resources Management}

HR has five key functions (Tracey, 2014):

1. Strategic HR

In reference to previous studies, strategic HR focuses on the relationship between HR systems and company performance. The aim of strategic HR is to improve organizational performance. There are three dimensions of strategic HR, namely efforts to enhance skills, enhance motivation, and enhance opportunities.

2. Staffing

The staffing domain conducts job analysis, competency assessment, recruitment, and selection. This staffing function is not only a matter of identifying employee needs and recruitment procedures but also plays a vital role in increasing the company's competitive positioning relative to other companies.

3. Training and development 
The function of training and development is not only to provide training for new employees in their adaptation process but also for long-term employees as a response to the dynamic changes of the workforce.

4. Performance appraisal

This function not only relates to performance appraisal but also the benefits of feedbacks provided by various parties. The parties here refer to direct reports from employees, colleagues, or superiors. HR also plays the role of explaining the assessment system, factors that influence the use of feedback, as well as the benefits of feedback for work performance.

5. Compensation and benefits

In this function, HR plays the role of explaining how incentive and reward systems influence employee outcome. Employee outcome consists of employee attitude, behavior, and performance.

To face the continuous development of technology, HRM faces various challenges, as stated by Lauby (2011). First, the organization has to evaluate the adoption of technology. Some organizations actively attempt to try the newest and most powerful technology. However, there are also organizations that wait until the technology's power/impact has been proven. Both actions contain weaknesses. For this reason, organizations should always stay proactive in evaluating new technology and must also be willing to take risks.

Second is balancing high tech and high touch. It is crucial for organizations to familiarize themselves with their need for technology. HR must be able to evaluate what function can be automated and what other functions must still be served.

The third is the curation of information. With the existence of big data, HR will experience a flood of information. Therefore, HR must have the means to filter essential and relevant information. This can also occur during the recruitment process, where recruiters may be flooded with candidate data. Therefore, it is essential for the recruiter to hone his or her ability to choose information from the recruitment platform or the data of prospective candidates.

Fourth is training accountability. As explained above, the use of technology in communicating or delegating tasks draws the question of whether or not employees understand the message being conveyed. HR has a responsibility to ensure that the communication between line managers and employees is carried out effectively. Proper communication can help to match expectations between superiors and subordinates.

In addition to the challenges described above, another challenge is the emergence of issues related to the use of technology for recruitment purposes (Pickard \& Whitehead, 2019). By using technology, access to information becomes more accessible without limitations of time and problems of geographical location. Therefore, there is a change in the relationship between employees and the organization. The use of websites, blogs, Facebook, and Twitter, for example, can build a community that works like a continuous loop. Human Resources Management plays a role in facilitating this communication loop. Therefore, HRM needs to have the skills related to information technology or social media.

From the perspective of technology use, HR has undergone considerable evolution. Initially, HR used a paper-based system. During the next phase, HR began to use computers (personal computers). In the third phase, HR began to use electronic database systems, followed by the use of web-based technology. The current use of information technology allows HR to integrate itself with information systems to collect, store, and analyze information (Bulmash, 2008). Slowly, HR has evolved into the human resources information system (HRIS).

Thus there is a shift in the role of HRIS. HRIS creates and records employees data, ensures employees comply with the law, the level managers can make predictions and plans for the future needs of HR, provide information to managers and HR so that they can manage knowledge and talent, provide information in order to synchronize HR activities with organizational strategic plans and provide relevant data to support organizational decision making.

\section{Conclusion}

Technology has become an integral part of organizations. Five areas have experienced change due to the use of technology, namely how and where to work, changes in work patterns, business activities, organizational decision-making, and the selection and recruitment process. The use of technology leads to organizational productivity. Therefore, HR, as a technology user, must continue to improve its capabilities 
in using technology. Numerous challenges arise for HRM as a result of technology use. For instance, HRM must be able to evaluate technology adoption that is carried out or will be carried out, balance high-tech and high-touch in organizational services, provide accurate information, conduct training in accordance with current needs of technology use - especially related to superior-subordinate communication, and lastly, HRM must have skills related to technology.

Human resources management must be able to adopt technology, evaluate the use of current technology, and adapt to the newly found role of HRM. HRM no longer plays a role in administrative or procedural matters, but plays a strategic role. HRM must be able to provide quality, accurate, and insightful data. In the end, HRM must be able to use technology to evaluate its effectiveness and increase its productivity.

\section{References}

Acharya, A., \& Singh, S. K. (2018). Big Data, Knowledge Co-Creation, and Decision Making in Fashion Industry. International Journal of Information Management, 42, 90-101. Retrieved from https://doi.org/10.1016/j.ijinfomgt.2018.06.008

Bulmash, J. (2008). Human Resources Management and Technology. Retrieved from https://catalogue.pearsoned.ca/assets/hip/.../0132270870.pdf

Cascio, W. F., \& Montealegre, R. (2016). How Technology Is Changing Work and Organizations. Annual Review of Organizational Psychology and Organizational Behavior, 3, 349-375. Retrieved from https://doi.org/10.1146/annurev-orgpsych-041015-062352

Christensen, C. M. (1997). The Innovator's Dilemma: The Revolutionary Book That Will Change The Way You Do Business. New York: HarperBusiness.

Dubravska, M., \& Solankova, E. (2015). Recent Trends in Human Resources Management in Selected Industry in Slovakia and The Czech Republic. Procedia Economics and Finance, 26(15), 1014-1019. Retrieved from https://doi.org/10.1016/S2212-5671(15)00924-7

Efron, L. (2017). How Technology Can Transform Workplace Humanity. Retrieved from https://www.forbes.com/sites/louisefron/2017/12/03/how-technology-can-transform-workplacehumanity/\#4d92bfde2f00

Ferri-Reed, J. (2014). Are Millennial Employees Changing How Managers Manage? The Journal for Quality and Participation, 37(2), 15-19.

Hauben, M., \& Hauben, R. (1995). The Netizens and The World of The Net: An Anthology on The History and Impact of The Net. Retrieved from http://www.columbia.edu/ rh120/

Heltzel, P. (2018). 12 Technology That Will Disrupt Bussiness in 2018. Retrieved from https://www.cio.com/article/3254744/technologies-that-will-disrupt-business.html

Keidanren Policy \& Action. (2018). Society 5.0: Co-Creating The Future. Retrieved from http://www.keidanren.or.jp/en/policy/2018/095.html

Lago, C. (2018). Which Company Are Using IOT in Southeast Asia. Retrieved from https://www.cio.com/article/3313098/which-companies-are-using-iot-in-southeast-asia.html

Lauby, S. (2011). 5 Challenges for Human Resources in A Digital World. Retrieved from https://www.americanexpress.com/en-us/business/trends-and-insights/articles/5-challenges-for-humanresources-in-a-digital-world-sharlyn-lauby/

Morris, C. (2018). Why Walmart and Other F500 Companies Are Using Virtual Reality to Train The Next Generation of $\{A\}$ merican Workers. Retrieved from https:/www.cnbc.com/2018/10/29/why-f500companies-use-virtual-reality-to-train-workers-of-the-future.html 
Pagani, M., \& Pardo, C. (2017). The Impact of Digital Technology on Relationships in A Business Network. Industrial Marketing Management, 67, 185-192. Retrieved from https://doi.org/10.1016/j.indmarman.2017.08.009

Pickard, G., \& Whitehead. (2019). 12 Voice Assistants Available Today to Help Organize Your Business. Retrieved from https://smallbiztrends.com/2017/12/voice-assistants-small-business.html

Robertson, K. (2000). Work Transformation: Integrating People, Space and Technology. Facilities, 18, 376382.

Sohag, R. A. (1992). The Impact of Technology on Work Groups. Work Study, 41(3), 14-15.

Tracey, J. B. (2014). A Review of Human Resources Management Research The Past 10 Years and Implications for Moving Forward. International Journal of Contemporary Hospitality Management, 26(5), 679-705. Retrieved from https://doi.org/10.1108/IJCHM-02-2014-0056

Vorley, Z. K. T. (2017). Big Data Text Analytics: An Enabler of Knowledge Management. Journal of Knowledge Management, 21(1). 